\title{
3-D FEM Wear Prediction of Brass Sliding against Bearing Steel Using Constant Contact Pressure Approximation Technique
}

\author{
Kunal Kumar Bose and Ramkumar Penchaliah \\ Machine Design Section, Department of Mechanical Engineering, Indian Institute of Technology Madras, India \\ *Corresponding author: Ramkumar Penchaliah (ramkumar@iitm.ac.in)
}

Manuscript received 10 July 2019; accepted 17 September 2019; published 31 October 2019

\begin{abstract}
For predicting the sliding wear in Pin-on-Disc (PoD) tribometer contact, a numerical wear simulation technique is presented in this paper. It is based on the Finite element method (FEM) which incorporates the Archard's wear law and the UMESHMOTION subroutine for calculating the wear depth for a 3-D PoD tribometer contact. FEM is utilized in solving the 3-D contact problem. The geometry is updated using the UMESHMOTION subroutine coupled with the Augmented Lagrangian-Eulerian (ALE) remeshing technique of ABAQUS. But, a significant disadvantage of FEM wear prediction is the enormous computational time required for performing 3-D analysis. Hence, to minimize the computational time, an approximation technique is introduced which accounts for the contact pressure evolution at the contact region. It decreased the simulation time and also preserved the accuracy of 3-D wear prediction. Finally, the results obtained from the simulations are compared with the experiments for brass-on-bearing steel PoD contact. An accuracy of $98.81 \%$ was obtained for the $10 \mathrm{~N}$ and $83.10 \%$ for the $30 \mathrm{~N}$ load.
\end{abstract}

\section{Keywords}

contact mechanics, finite-element method, sliding, wear, UMESHMOTION

\section{Introduction}

Wear is defined as the loss or transfer of material when there is a sliding motion between the contacting surfaces. A prevalent wear mechanism in mechanical parts is sliding wear. It is common in tyres, brakes, bearings, etc. It involves plowing and cutting action, adhesion, three-body wear debris formation, subsurface cracking, material transfer, surface roughness changes, tribo-chemical film formation, and allied processes [1]. Hence sliding wear prediction is a complex problem in engineering.

Wear in a tribological system is influenced by a number of variables and parameters. Wear modeling involves assembling these variables into mathematical forms, which can be used for wear rate predictions. There are about 300 equations for friction and wear which are found in the literature [2]. Among them, one of the most commonly used sliding wear prediction equation is the Archard's wear law [3]. This equation takes into consideration the load, sliding distance and material properties of the two surfaces in contact.

Experiments are performed using the PoD tribometer and similar related tribometer rigs for predicting the sliding wear. The tribological test conditions used in these experiments should mimic the actual conditions and the experiments have to be run for long time periods. However, with the advancements in computing power, numerical wear simulation has gained popularity, which has reduced the costs and time involved in experiments. Numerical wear simulation includes solving a non-linear contact problem and also continuously updating the geometry and mesh due to material removal. Solving the nonlinear contact problem is one of the most challenging problems in contact mechanics. Many techniques have been used in solving contact problems like the Green's function molecular dynamics (GFMD) [4], the Winkler model [5], Boundary element method (BEM) [6, 7], Archard-Based Models [8], Global Incremental Wear Model (GIWM) [9], Finite Element Method (FEM) [10-12] etc. All these techniques have some advantages and disadvantages depending on simulation time and accuracy.

In this paper, the 3-D PoD contact problem is solved using FEM. Podra et al. [5] used FEM to predict the wear of 2-D spherical pin-on-disc unlubricated steel sliding contacts. Hegadekatte et al. [13] used FEM to predict the dry sliding wear of both 2-D and 3-D deformable contact surfaces. Öqvist et al. [14] also performed the FEM wear prediction of a cylindrical steel roller oscillating against a steel plate. Similarly, McColl et al. [15] used FEM to predict fretting wear on a 2-D cylinderon-flat surface. Arjmandi et al. [16] also used finite element modelling in 3-D woven textiles to predict sliding wear.

The differential Archard's law is implemented after solving the FEM contact problem for calculating the incremental wear 
depth. The wear depth is applied to the FEM contact nodes for simulating the material removal process. Öqvist et al. [14] applied the wear depth to the nodes without performing any remeshing between the wear increments. This limits the maximum wear depth that can be applied to the contact nodes as a higher wear depth may distort the contact elements and induce errors in the FEM results. This problem can be addressed by using the ALE (Augmented Lagrangian Eulerian) remeshing technique of ABAQUS coupled with the UMESHMOTION user subroutine. Hegadekatte et al. [9] applied this procedure for wear simulation in tribometers. Arjmandi et al. [16] also used ALE coupled with UMESHMOTION for sliding wear predictions.

However, the large computational time requirement is a significant drawback in FEM wear simulations. The reason for that is that each wear cycle requires solving a non-linear contact problem and an update of the geometry due to material removal. Moreover, the simulations have to be run for a large number of cycles to simulate the wear process. To address this, plane strain conditions were assumed and less costly 2-D simulations were performed instead of 3-D simulations [17, 18]. However, for sphere-on-flat contact of PoD tribometers, this approximation would not mimic the actual contact condition. Therefore, the error obtained from 2-D prediction would be always higher. Hence, for reducing the probability of error, 3-D simulations have to be performed. But, in 3-D wear simulations, the problem of large computational time becomes more severe. Hence, for performing 3-D wear simulations, an approximation technique has to be introduced, which lessens the simulation time and also maintains the wear prediction accuracy.

For minimizing the simulation time of wear simulations different techniques have been used in literature. Podra et al. [5] used a maximum allowable time increment approach, to minimize the computational time. Curreli et al. [19] used the sub modelling approach to minimize the time required in FEM wear simulations. Similarly, Kim et al. [20] and Mukras et al. [21] applied the extrapolation approach for decreasing the simulation time in oscillating contacts. In this approach, one FEM wear cycle was extrapolated to ' $n$ ' wear cycles. This reduced the total FEM cycles simulated. Bortoleto et al. [22] used a technique in which he simulated one wear cycle and extrapolated the wear volume for the entire sliding duration. However, he did not account for the changes in the contact pressure and other contact stresses during the wear process which resulted in higher error. In the actual case, the contact pressure and other stresses change continuously as wear progresses. A method that considers the variation of the contact pressure during wear prediction is therefore suggested.

Hence, the objective of this paper is to perform wear prediction for 3-D PoD tribometer contact. In order to achieve this a combination of FEM + (UMESHMOTION + ALE), + approximation technique is used. FEM is applied for solving the non-linear contact problem while UMESHMOTION + ALE is used to perform the geometry update due to material removal. Finally, in order to decrease the simulation time while keeping the accuracy, an approximation technique is proposed. The approximation technique used, accounts for the evolution of pressure in the contact region. Finally, the simulation procedure is validated using experiments performed for brass-on-bearing steel PoD contact.

\section{Experimental procedure and results}

Experiments were carried out using the PoD (Fig. 1) tribometer to evaluate the accuracy of the numerical wear prediction. ASTM G99-05 standard was used to carry out the experiments. The experiments were performed using brass as pin material and bearing steel (AISI 52100) as disc surface. The chemical composition of AISI 52100 bearing steel in \% is (C $=0.90$ 1.20, $\mathrm{Mn}=0.30-0.75, \mathrm{Si}=0.10-0.35, \mathrm{~S}=0.04, \mathrm{P}=0.04, \mathrm{Cr}=1-1.60, \mathrm{Fe}$ $=$ Remainder). While, for brass the chemical composition in $\%$ is $(\mathrm{Cu}=62.0-64.0, \mathrm{Al}=0.0-0.05, \mathrm{Fe}=0.0-0.10, \mathrm{~Pb}=0.0-0.10, \mathrm{Ni}=0.0-$ $0.30, \mathrm{Sn}=0.0-0.10, \mathrm{Zn}=$ Remainder). The properties of brass and AISI 52100 bearing steel are shown in Table 1.

Tests were carried out under dry sliding conditions for normal loads of $10 \mathrm{~N}, 20 \mathrm{~N}$ and $30 \mathrm{~N}$. At least two repetitions were done for each loading condition. The sliding velocity was fixed at $0.4 \mathrm{~m} / \mathrm{s}$ and the pin was allowed to slide for a distance of $500 \mathrm{~m}$. A load cell was used to measure the frictional force. The coefficient of friction (CoF) was obtained by dividing the friction force with the applied normal load. Figure 2 shows the response of coefficient of friction obtained the three loads. The average steady-state CoF was used for wear prediction calculations.

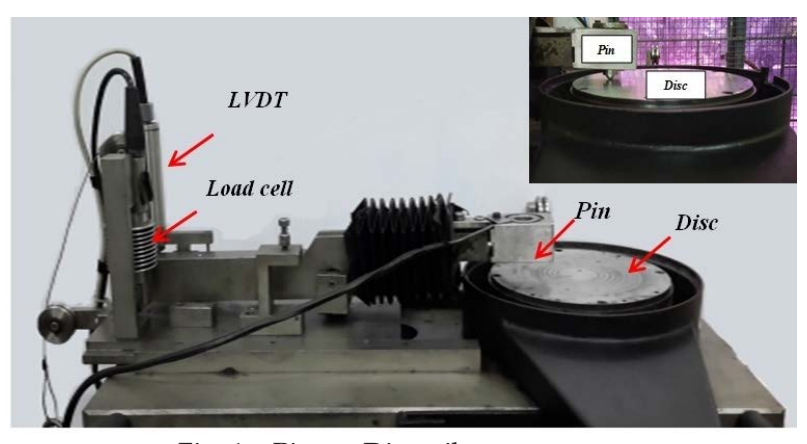

Fig. 1 Pin-on-Disc tribometer setup

Table 1 Dimension and properties of the pin and disc material

\begin{tabular}{lcc}
\hline Properties & Pin & Disc \\
\hline Materials & Brass & AISI 52100 \\
Elastic Modulus $(\mathrm{GPa})$ & 100 & 200 \\
Density $\left(\mathrm{kg} / \mathrm{m}^{3}\right)$ & 8520 & 7810 \\
Surface Roughness, $\mathrm{Ra}(\mu \mathrm{m})$ & 0.02 & 0.30 \\
Hardness $(\mathrm{HRC})$ & 20 & 60 \\
Poisson's ratio & 0.33 & 0.3 \\
Dimensions $(\mathrm{mm})$ & 10 dia & 165 dia $\times 8$ \\
& & thickness \\
\hline
\end{tabular}

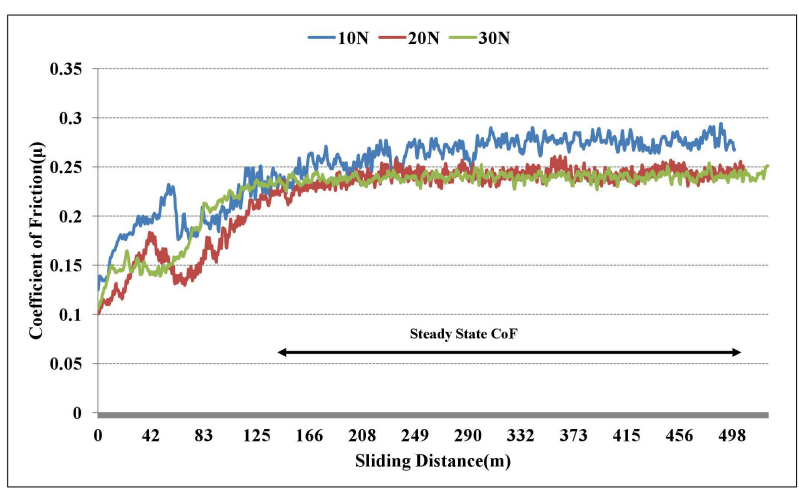

Fig. 2 The $\operatorname{CoF}(\mu)$ response for $500 \mathrm{~m}$ sliding distance at $10 \mathrm{~N}$, $20 \mathrm{~N}$ and $30 \mathrm{~N}$ loads 
In the bearing steel disc, immeasurable wear occurred. This is because of the higher hardness of bearing steel disc relative to the brass pin. Therefore, the wear of disc was neglected in the FEM wear calculations. The mass loss of the brass pins were obtained by weighing them before and after the tests. The wear volume of the pin is calculated using the mass lost. Finally, the wear volume was used to obtain the dimensional wear coefficient with the help of Archard's wear law [3], given by

$$
\frac{V}{S}=k \frac{W}{H}
$$

\section{Where $V=$ Wear Volume \\ $s=$ sliding distance}

$$
\begin{aligned}
& k=\text { wear coefficient } \\
& W=\text { Applied normal load } \\
& H=\text { hardness of the pin }
\end{aligned}
$$

An optical microscope was used to measure the pin wear scar diameter. From the wear scar diameter, the pin wear depth is derived using the spherical cap formula. The optical images of brass wear scar at varying loads are presented in Fig. 3. The coefficient of friction ( $\mathrm{CoF}$ ), loss of volume, wear scar diameter along with the wear depth obtained from the experiments are shown in Table 2.

It is observed in Table 2 that the volume loss, wear scar diameter and wear depth increased with load. Finally, the average dimensional wear coefficients were obtained for the
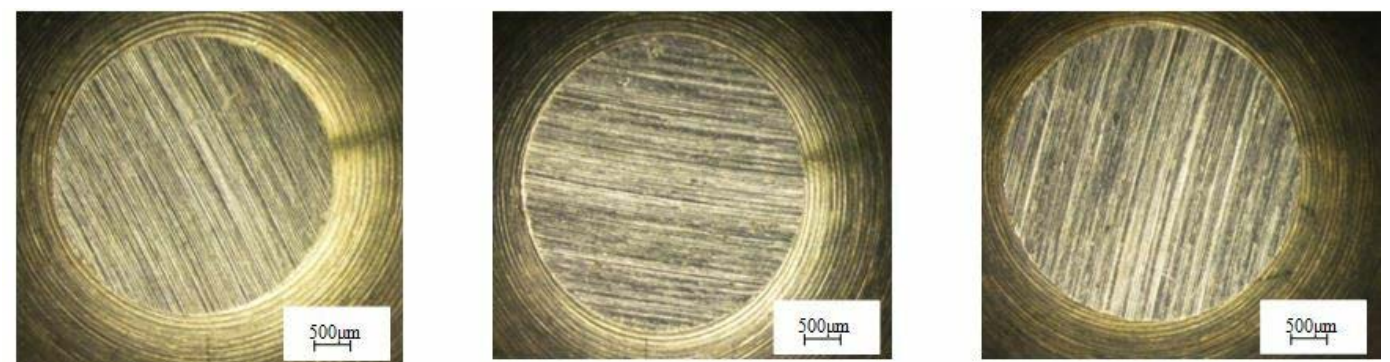

Fig. 3 Wear scar optical images of brass pin samples for (a) 10N, (b) 20N and (c) 30N loads

Table 2 The volume loss, CoF, wear scar diameter and wear depth of the brass pin samples

\begin{tabular}{ccccc}
\hline Load & $\operatorname{CoF}(\mu)$ & Volume Loss $\left(\mathrm{mm}^{3}\right)$ & Wear Depth $(\mu \mathrm{m})$ & Wear scar dia $(\mu \mathrm{m})$ \\
\hline 10 & 0.24 & 0.2144 & 377.95 & 3805 \\
20 & 0.22 & 0.3670 & 493.00 & 4329 \\
30 & 0.22 & 0.5501 & 602.46 & 4758 \\
\hline
\end{tabular}

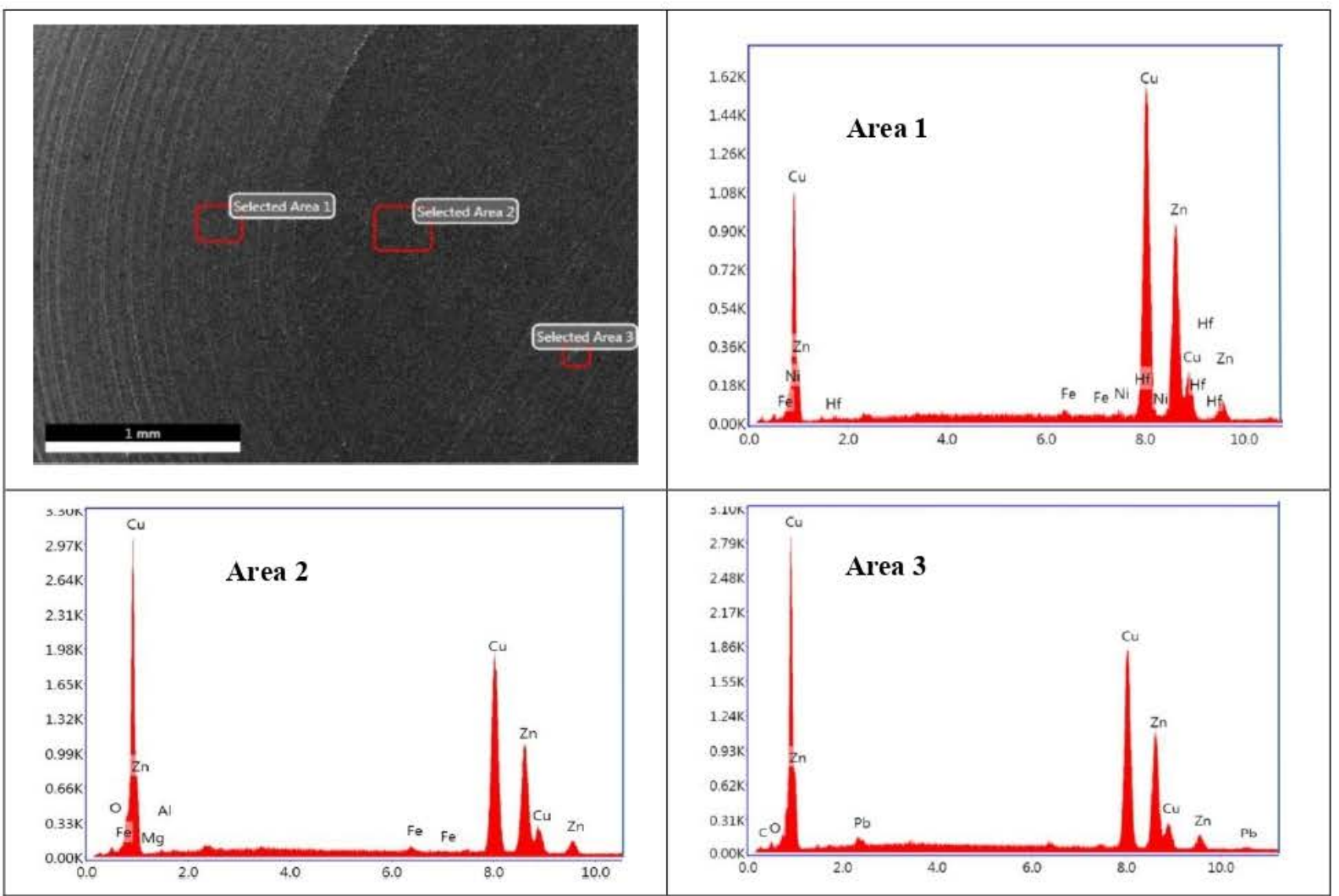

Fig. 4 Energy-dispersive X-ray spectroscopy (EDS) analysis for $20 \mathrm{~N}$ load 
experiments after a sliding distance of $500 \mathrm{~m}$. Average wear coefficients of $k_{H}=4.28 \times 10^{-8} \mathrm{~mm}^{3} / \mathrm{Nm}, 3.67 \times 10^{-8} \mathrm{~mm}^{3} / \mathrm{Nm}$ and $3.72 \times 10^{-8} \mathrm{~mm}^{3} / \mathrm{Nm}$ were obtained for $10 \mathrm{~N}, 20 \mathrm{~N}$ and $30 \mathrm{~N}$ loads respectively. The wear coefficient $k_{H}$ and $\operatorname{CoF}(\mu)$ values were provided as input values to the numerical simulation. Finally, the simulation wear depth is verified with the experiments.

Figure 4 shows Energy-dispersive $\mathrm{X}$-ray spectroscopy (EDS) analysis done at the areas 1, 2 and 3 for the $20 \mathrm{~N}$ load. Area1 was taken away from the wear scar and areas 2 and 3 were taken on the wear scar. It has been observed that oxygen is present in areas 2 and 3 which were not seen in area 1 . Hence, it implies that oxidation also has occurred during sliding wear. Similar patterns were also observed for the $10 \mathrm{~N}$ and $30 \mathrm{~N}$ loads as well. The effect of oxidation on wear is included in the wear coefficient.

The SEM (Scanning Electron Microscope) micrographs of the brass pins in Fig. 5 show that predominantly abrasive wear has occurred along the sliding direction for $10 \mathrm{~N}, 20 \mathrm{~N}$ and $30 \mathrm{~N}$ loads.

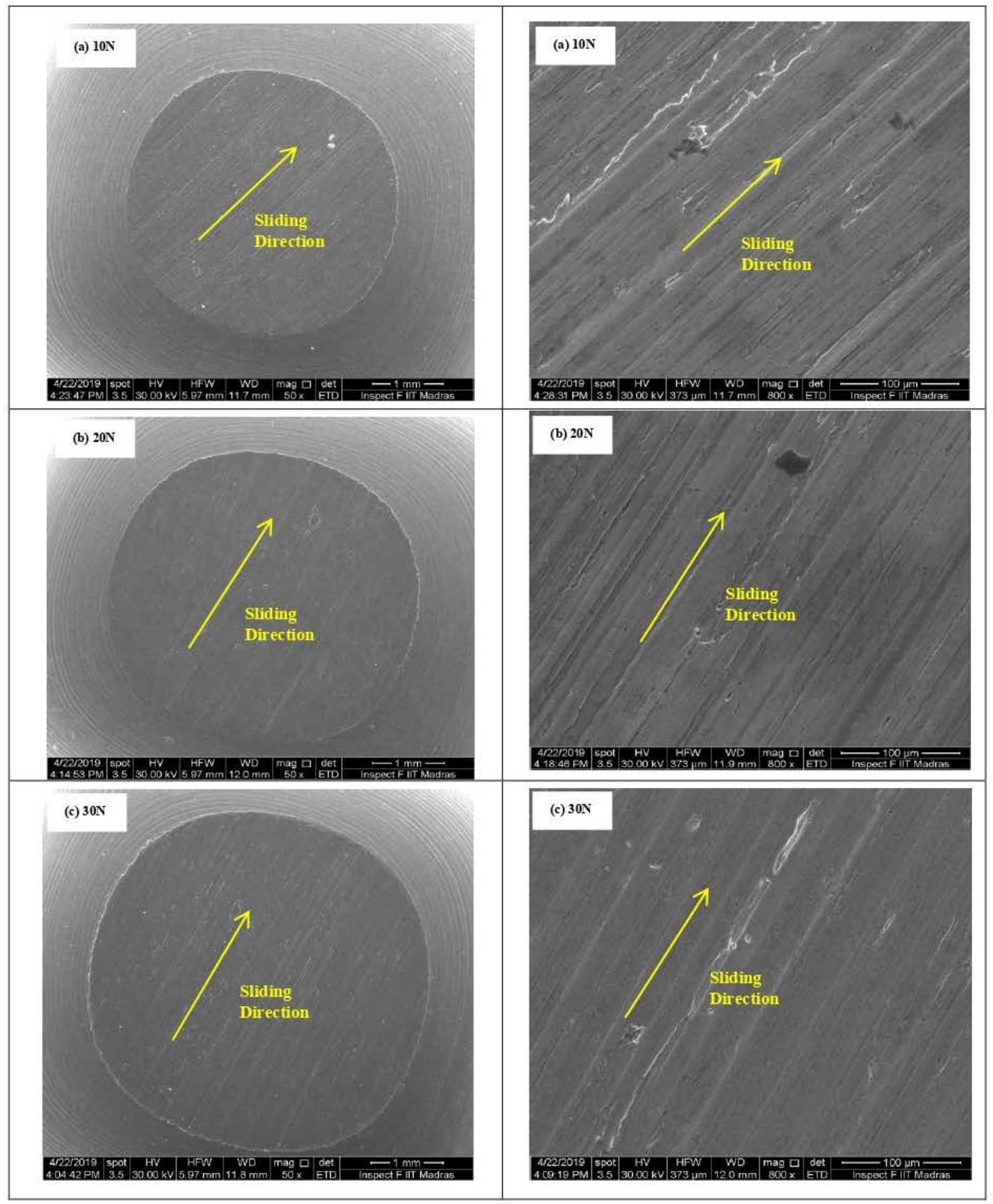

Fig. 5 SEM micrographs for (a) 10N, (b) 20N and (c) 30N loads 


\section{Numerical wear modelling}

3.1 Differential Archard's equation

The numerical wear prediction depends on the material properties and contact information of the contacting surfaces. The wear model which takes into consideration these parameters for wear rate calculations is the Archard's model [3]. Eq. (2) is implemented for calculating the wear depth from the Archard's wear model.

$$
\frac{w}{s}=k_{H} P
$$

\section{Where}

$w=$ Wear depth i.e. $V / A$

$P=$ Contact Pressure i.e. W $/ A$

$k_{H}=$ dimensional wear coefficient i.e. $\mathrm{k} / \mathrm{H}$

The wear process can be considered as an initial value problem. Hence, the Archard's wear law can be described in the differential form as

$$
\frac{d w}{d s}=k_{H} P
$$

Integration of the Archard's law according to the Euler integration scheme for a specified sliding distance, gives

$$
w_{n+1}=w_{n}+k_{H} P_{n} \Delta s
$$

Here $w_{n}$ and $w_{n+1}$ are the wear depths at $n^{\text {th }}$ and $n+1^{\text {th }}$ wear increment. The wear depth $w_{n+1}$ for a specific incremental sliding distance $\Delta s$, depends on the wear depth at the previous step $w_{n}$ the dimensional wear coefficient $k_{H}$, and the contact pressure $P_{n}$ of the contacting surfaces. The dimensional wear coefficient $k_{H}$ is attained from experimental results and the FEM contact problem is solved to get the contact pressure $P_{n}$ between the contacting surfaces.

The pressure calculated from the FEM results is validated using the well-known Hertz equations for elastic point contacts [23]. The contact pressure distribution according to Hertz is given by

$$
\begin{aligned}
& P(r)=P_{0} \sqrt{1-\frac{r^{2}}{a^{2}}} \\
& P_{0}=\left(\frac{6 W E^{* 2}}{\pi^{3} R^{2}}\right)^{\frac{1}{3}} \\
& a=\left(\frac{3 W R}{4 E^{*}}\right)^{\frac{1}{3}}
\end{aligned}
$$

Where,

$P_{0}=$ Maximum contact pressure

$a=$ Contact radius

$W=$ Load normal to the surface

$R=$ Radius of Pin

$E^{*}=$ elastic modulus of the two materials combined

$E^{*}=\left(\frac{1-\left(v^{f}\right)^{2}}{E^{f}}+\frac{1-\left(v^{c}\right)^{2}}{E^{f}}\right)^{-1}$

$E^{f}, E^{c}=$ Elastic moduli of the two materials

$v^{f}, v^{c}=$ Poisson's ratio of the two materials

\subsection{Geometry update}

The wear depth calculated from the Archrad's wear law is applied to the contacting nodes using the user-defined FORTRAN subroutine of ABAQUS known as UMESHMOTION [24]. UMESHMOTION is coded to shift the nodes in contact by the wear increment $w_{n+1}$ shown in Eq. (4). The wear depth is applied as mesh constraints to the surface nodes. The shifting of the nodes might result in distortion of the contacting elements which can affect the FEM results as seen in Fig. 6. Hence, these elements have to be re-meshed near the contact region. This is performed in ABAQUS with the help of Arbitrary LagrangianEulerian (ALE) adaptive meshing scheme. The adaptive
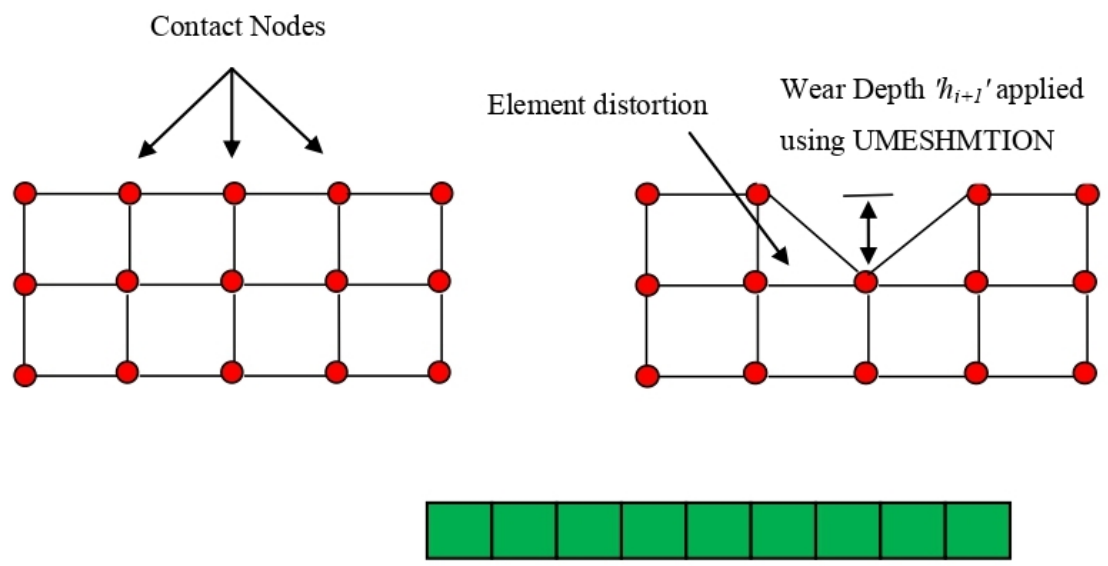

Mesh distortion in Lagrangian simulation
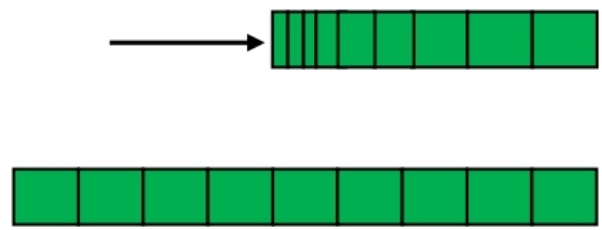

Mesh quality maintained in ALE simulation

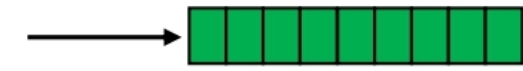

Fig. 6 Wear depth applied at the contact nodes using UMESHMOTION 
meshing algorithm is used to relocate the mesh without creating new elements in the domain. Hence, it enables to maintain the quality of the mesh during the analysis, which is not possible using the standard Lagrangian analysis as seen in Fig. 6. It combines pure Lagrangian and pure Eulerian characteristics. For performing the contact analysis the Lagrangian approach is utilized while the element distortion is prevented by the Eulerian approach. Hence, the combination of UMESHMOTION + ALE technique enables in updating the geometry and contact pressure while preserving the mesh quality during the analysis.

\subsection{Sliding wear simulation method}

Thus, the sliding wear simulation is an incremental method comprising of three steps, which form a FEM wear simulation cycle. Firstly, the non-linear PoD contact problem is solved by means of FEM. Secondly, the contact pressure $P_{n}$ obtained from FEM and wear coefficient $k_{H}$ obtained from experiments, are utilized in calculating the incremental wear depth utilizing the differential Archard's law for a specified sliding distance. Finally, the ALE + UMESHMOTION technique is implemented for updating the pin geometry. All these steps have to be repeated until the maximum limit of sliding is achieved. These steps are implemented in ABAQUS using PYTHON scripting. The steps involved in sliding wear simulation is presented in Fig. 7.

\section{3-D FEM wear model}

A 3-D FEM model of PoD tribometer is created using ABAQUS as presented in Fig. 8. The pin and disc contact is considered as elastic. The radius of the pin is taken as $5 \mathrm{~mm}$ as used in the experiments. Since the PoD contact is axi-symmetric; it is simplified into contact between an axi-symmetric

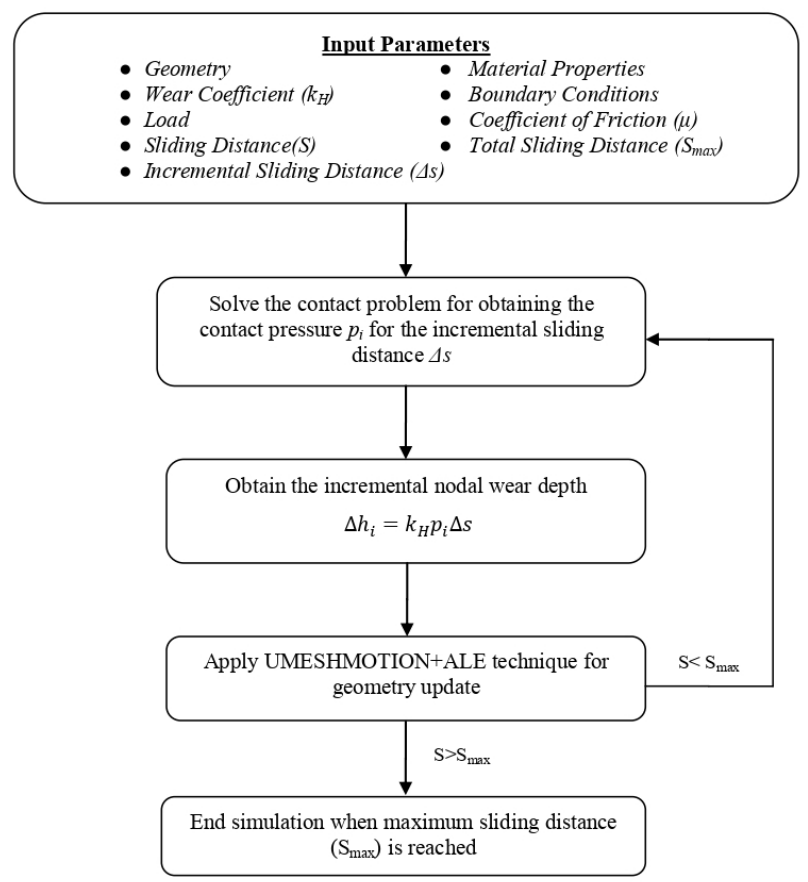

Fig. 7 Wear simulation steps using PYTHON scripting

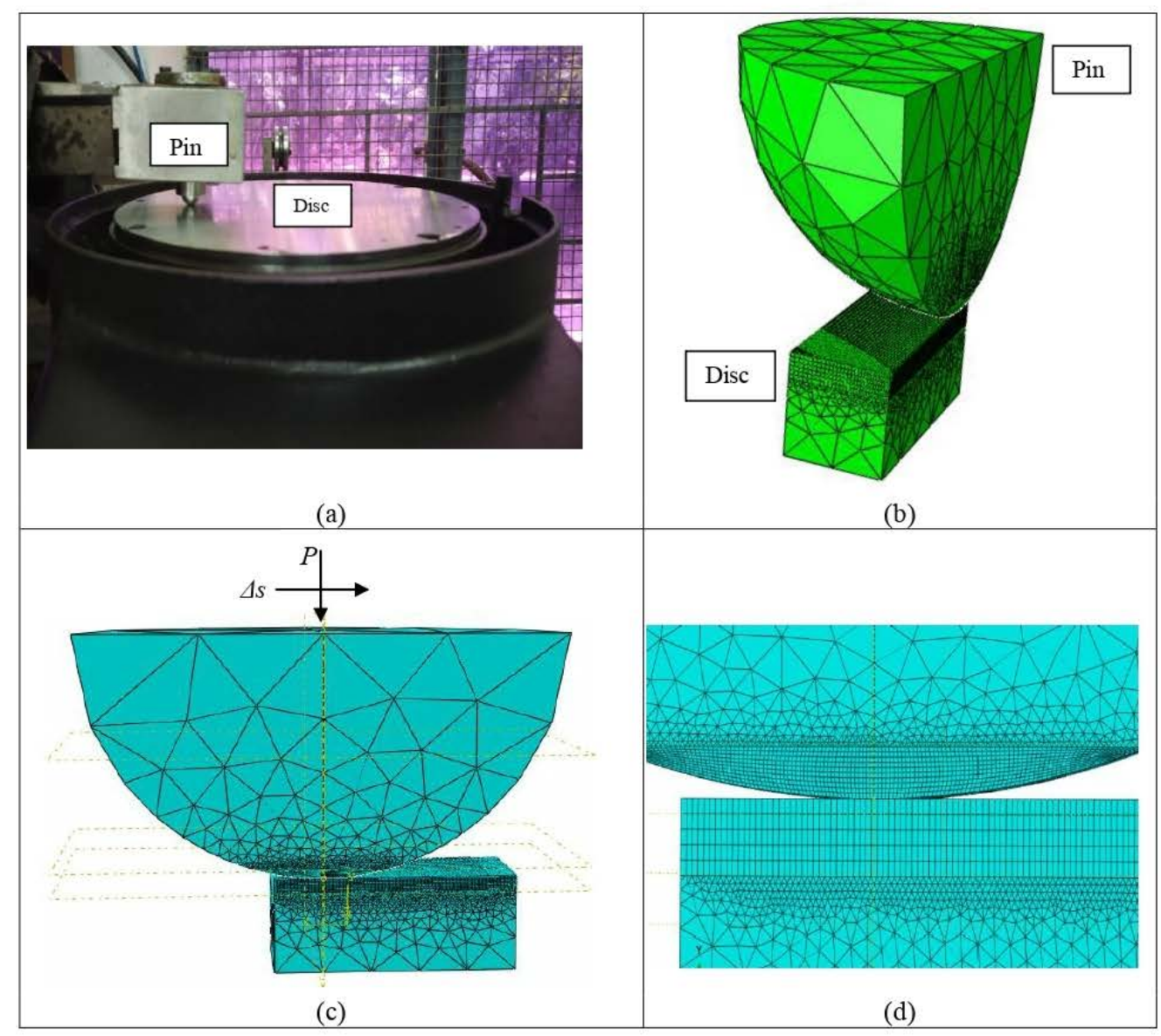

Fig. 8 (a) Experimental PoD contact (b) 3-D FEM PoD model (c) Boundary condition applied to the FEM model (d) Mesh distribution at the contact region 
hemisphere and flat surface. This decreased the simulation time. To further reduce the computational time of simulations, near the contact area a fine mesh is created and distant from the contact area a course mesh is used. 8-node linear brick, reduced integration, hourglass control (C3-D8R) elements are used in the contact region. 4-node linear tetrahedron (C3-D4) elements are used distant from the contact area. A mesh size of $20 \mu \mathrm{m}$ is used in the contact region. Load ' $W$ ' is applied as boundary condition to the pin. The pin is allowed to slide for an incremental sliding distance of $2 \mathrm{~mm}(\Delta s)$, during a given wear increment cycle. The dimensions and material properties of brass and bearing steel from Table 3, are given as input to the model. The wear of the bearing steel disc is not considered in the simulations, as in the experiments.

Penalty contact algorithm is implemented for solving the PoD contact problem. The pin is considered as slave and the disc as master surface. Coulomb's friction law is used to describe the tangential behavior. The experimental values are used for the coefficient of friction. The contact pressure obtained from FEM is utilized in calculating the incremental wear depth ' $w_{n+1}$ ' at the contacting nodes using Archard's law. The wear depth is then utilized in updating the geometry of the pin using the UMESHMOTION + ALE technique. This procedure is repeated for the next wear cycles till the maximum limit of sliding distance i.e. $500 \mathrm{~m}$ is achieved.

\section{Results and discussions}

\subsection{Mesh validation}

The accuracy of the numerical wear prediction depends on the contact pressure obtained from FEM. Hence, mesh convergence study is performed to validate if the FEM contact pressure obtained is close to the Hertz analytical solution. For brass-on-bearing steel contact, the maximum contact pressure from Hertz analytical solution is calculated. Then, the error in the FEM contact pressure for various mesh sizes is matched with Hertz solution. It can be seen in Table 3 that on decreasing mesh size from 200 to $20 \mu \mathrm{m}$, the error in the FEM contact pressure reduces to $0.7 \%$. The contact pressure distribution at various mesh sizes is shown in Fig. 9(a). Again, considering 20 $\mu \mathrm{m}$ mesh size, the error in the maximum contact pressure is also calculated at different loads. It can be observed in Table 4 that the error in the FEM contact pressure is less than $4 \%$ for the three loads. The contact pressure distribution at various loads obtained from FEM is also shown in Fig. 9(b). Hence a mesh size of $20 \mu \mathrm{m}$ is used during the simulations.

\subsection{Constant contact pressure approximation}

Every FEM wear cycle comprises of solving a non-linear contact problem and then updating the geometry of the pin using the UMESHMOTION + ALE technique. During each FEM cycle, the pin is allowed to slide for an incremental sliding distance $(\Delta s)$ of $2 \mathrm{~mm}$. The incremental sliding distance influences the accuracy of wear depth ' $w_{n+1}$ '. A larger ' $\Delta s^{\prime}$, reduces the accuracy of the numerical wear prediction while

Table $4 \%$ Error between Hertz and FEM contact pressure for variation of the load from $10 \mathrm{~N}$ to $30 \mathrm{~N}$ for brass-onbearing steel contact

\begin{tabular}{cccc}
\hline Load (N) & $\begin{array}{c}\text { Hertz Contact } \\
\text { Pressure (MPa) }\end{array}$ & $\begin{array}{c}\text { FEM Contact } \\
\text { Pressure (MPa) }\end{array}$ & Error (\%) \\
\hline 10 & 753.12 & 758.91 & 0.76 \\
20 & 948.88 & 975.90 & 2.76 \\
30 & 1086.20 & 1122.88 & 3.37 \\
\hline
\end{tabular}

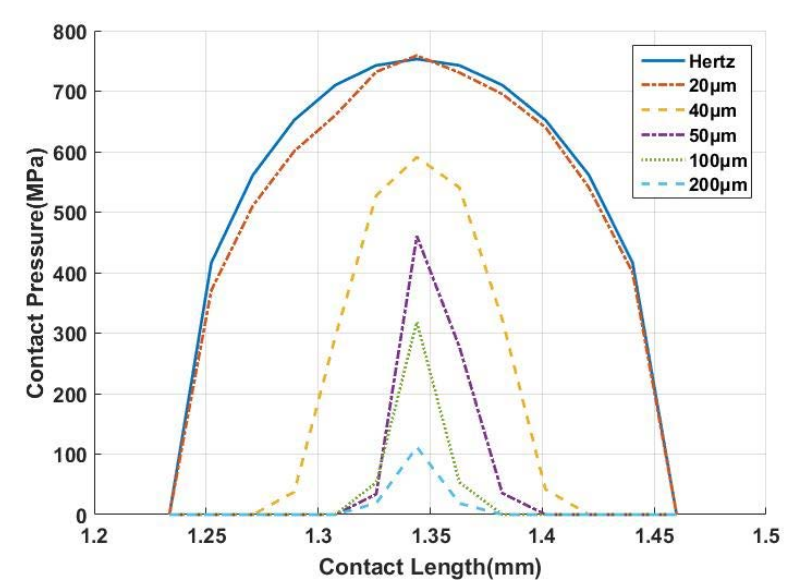

(a)

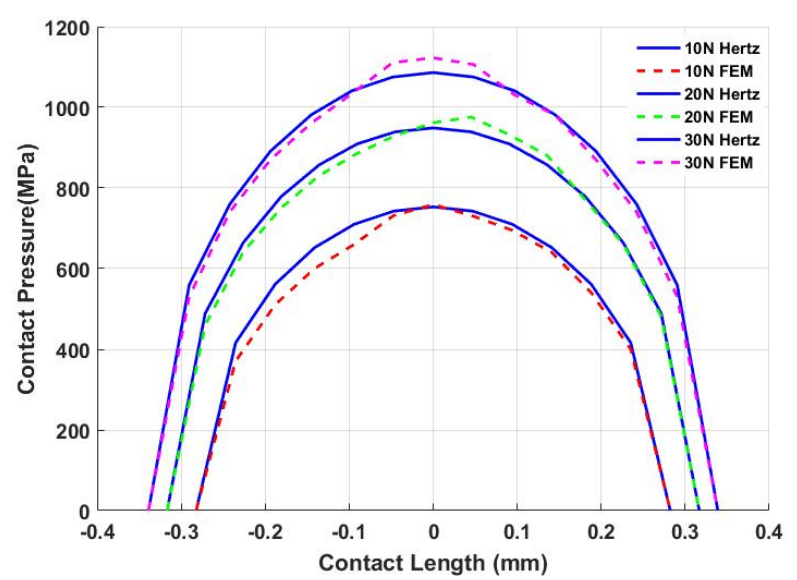

(b)

Fig. 9 FEM contact pressure distribution with variation of (a) mesh size from 200 to $20 \mu \mathrm{m}$ (b)load from 10 to $30 \mathrm{~N}$

Table $3 \%$ Error between Hertz and FEM contact pressure for mesh size variation from 200 to $20 \mu \mathrm{m}$ for brass-on-bearing steel contact

\begin{tabular}{cccc}
\hline Mesh size $(\mu \mathrm{m})$ & Hertz Contact Pressure $(\mathrm{MPa})$ & FEM Contact Pressure $(\mathrm{MPa})$ & Error $(\%)$ \\
\hline 200 & 753.12 & 111.71 & 85.16 \\
100 & 753.12 & 318.34 & 57.73 \\
50 & 753.12 & 460.55 & 38.84 \\
40 & 753.12 & 590.93 & 21.53 \\
20 & 753.12 & 758.91 & 0.768 \\
\hline
\end{tabular}


a lower ' $\Delta s$ ' increases the computational time. Each FEM wear cycle required about 30 minutes in a $16 \mathrm{~GB}$ workstation. Hence, for $500 \mathrm{~m}$, it would require about $(500 \times 1000) / 2=250000 \mathrm{FEM}$ cycles, i.e., about 5208 days. Therefore, the large computational time required for obtaining accurate results is one of the major drawbacks of FEM based wear prediction. In order to reduce the simulation time, Bortoleto et al. [22] extrapolated the wear volume obtained after 1 cycle for the entire sliding distance. But this method does not account for the variation of contact parameters such as contact pressure, contact area and other contact stresses with cycles. Hence, the error in wear depth obtained by this method will be larger. In order to decrease the simulation time of 3-D simulations, without compromising the accuracy of wear prediction, a technique 'constant contact pressure approximation' is proposed.

In Fig. 10(a) \& (b) the variation of average contact pressure for the brass-on-bearing steel contact for $10 \mathrm{~N}$ load after $200 \mathrm{FEM}$ cycles is shown. It can be noted that during the initial cycles there is a sharp decrease in contact pressure. After that, contact pressure becomes almost constant at the contact area. At the beginning, due to the point contact between the pin and disc a high contact pressure is developed. But as wear progresses, the contact changes from point to surface contact with the increase in the contact area. Hence, the contact pressure gets distributed over a larger area and it starts becoming constant. A similar variation in contact pressure was also observed by Curreli et al. [19]. Therefore, to minimize the simulation time of 3-D simulations, the simulations are run for the number of cycles during which there is a large variation of contact pressure. For the brass-on-bearing steel contact at $10 \mathrm{~N}$ load, change in average contact pressure becomes less than $1 \mathrm{MPa}$ after 120 FEM cycles as seen in Table 5. Hence, the simulations are run for only 120 cycles. After 120 FEM cycles, using $17.88 \mathrm{MPa}$ as the constant contact pressure, the Archard's law is utilized for obtaining the wear depth in the remaining cycles. As the contact pressure is considered constant, the wear depth is only a linear function of sliding distance. Hence, on modifying the Archard's wear law from Eq. (8) to Eq. (9) we obtain the total wear depth.

$$
w=\int k_{H} p d s
$$

Considering the wear coefficient $k_{H}$ and contact pressure $p$ as constant, the Archard's wear law is modified as equation

$$
w=k_{H} p \int d s
$$

A similar contact pressure variation can also be seen in the $20 \mathrm{~N}$ load case as seen in Fig. 11(a) \& (b). After a large drop in pressure in the initial cycles, the pressure variation goes below $1 \mathrm{MPa}$ after $160 \mathrm{FEM}$ cycles. Hence, the wear simulations are carried out for 160 cycles after which the Archard's model is directly applied. A similar analysis is also done for $30 \mathrm{~N}$ load

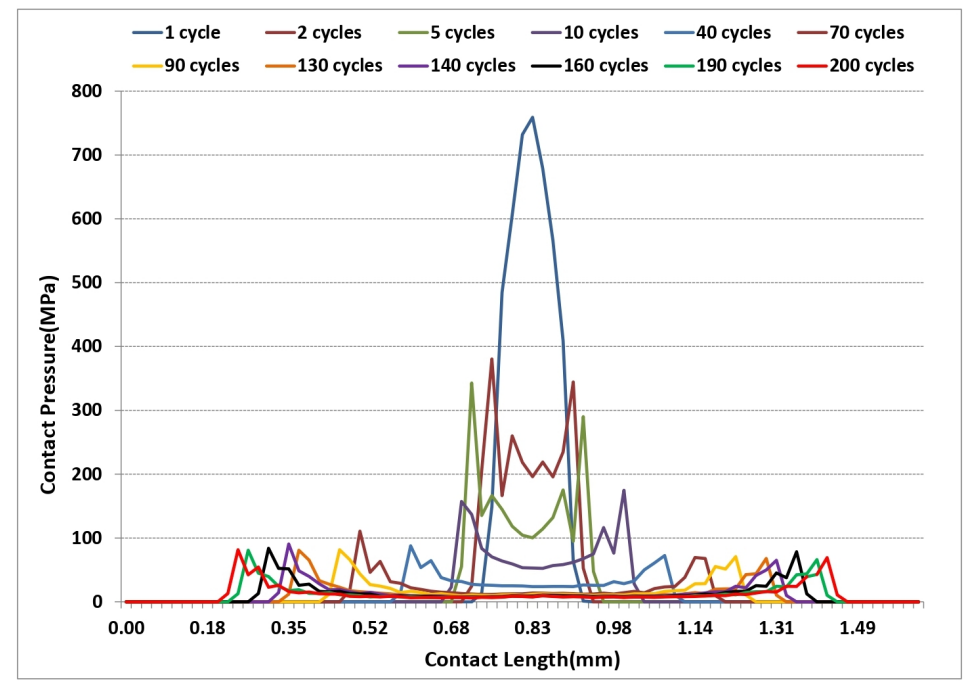

(a)

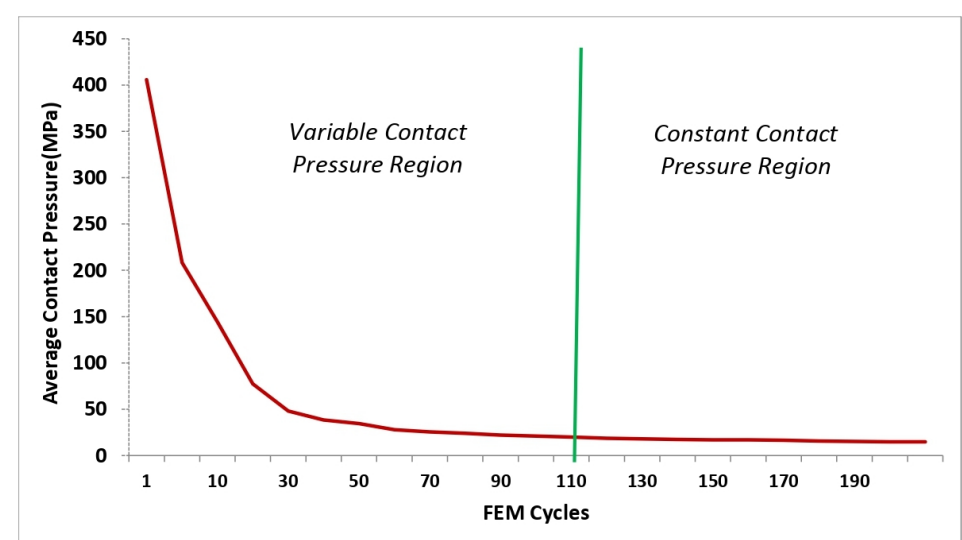

(b)

Fig. 10 (a) Contact Pressure (b) Average contact pressure distribution for brass-on-bearing steel contact for 10N and 200 FEM cycles 


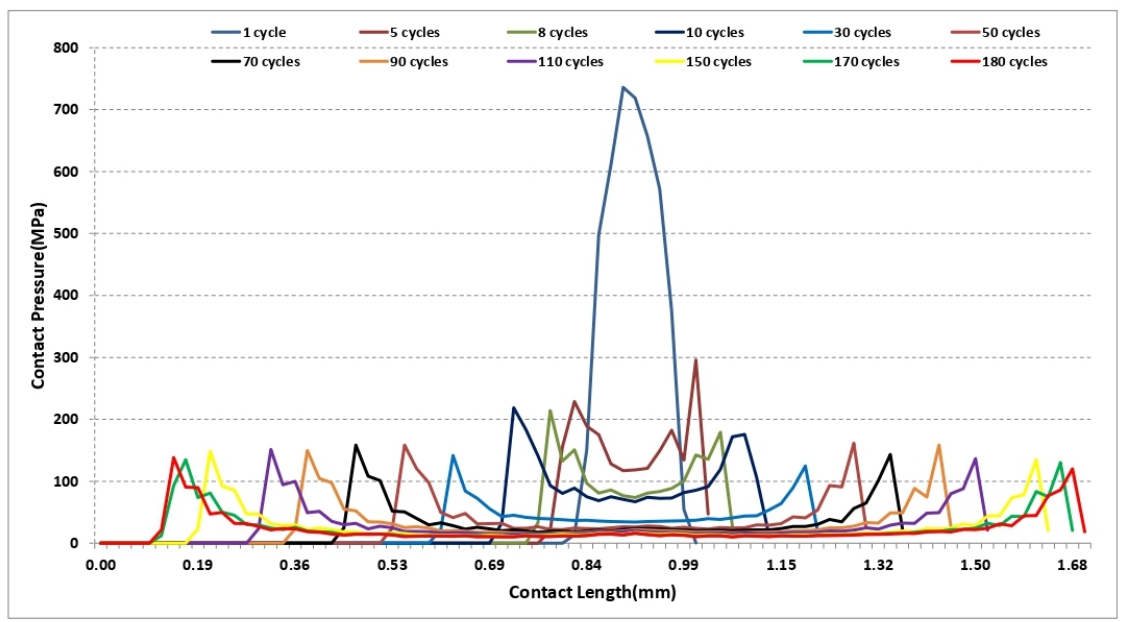

(a)

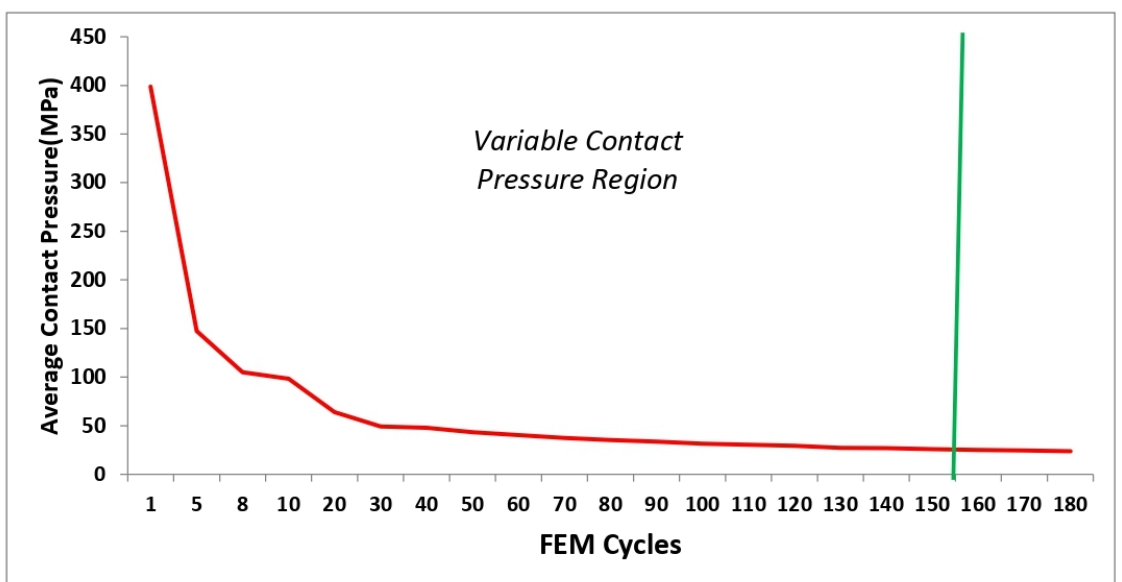

(b)

Fig. 11 (a) Contact Pressure (b) Average contact pressure distribution for brass-on-bearing steel contact for 20N and 180 FEM cycles

Table 5 Change in average contact pressure for brass-on-bearing steel contact with FEM cycles for the $10 \mathrm{~N}$ load

\begin{tabular}{ccc}
\hline Cycles & $\begin{array}{c}\text { Average Contact } \\
\text { Pressure (MPa) }\end{array}$ & $\begin{array}{c}\text { Change in Average Contact } \\
\text { Pressure (MPa) }\end{array}$ \\
\hline 1 & 405.72 & \\
4 & 208.25 & 197.46 \\
8 & 144.42 & 63.82 \\
10 & 77.36 & 67.06 \\
20 & 48.00 & 29.35 \\
30 & 38.32 & 9.68 \\
40 & 34.40 & 3.92 \\
50 & 27.79 & 6.61 \\
60 & 25.40 & 2.39 \\
70 & 24.02 & 1.37 \\
80 & 22.16 & 1.86 \\
90 & 20.97 & 1.19 \\
100 & 19.97 & 0.99 \\
110 & 18.52 & 1.45 \\
120 & 17.88 & 0.63 \\
130 & 17.31 & 0.56 \\
140 & 16.94 & 0.37 \\
150 & 16.87 & 0.07 \\
160 & 16.55 & 0.32 \\
170 & 15.64 & 0.90 \\
180 & 15.17 & 0.47 \\
190 & 14.78 & 0.39 \\
200 & 14.76 & 0.01 \\
\hline
\end{tabular}

case where the contact pressure becomes stable after 190 FEM cycles. Hence, by monitoring the contact pressure variation, the computational time involved in 3-D simulations can be greatly minimized.

5.3 Stress distribution at the contact region

In this section, the variation of contact pressure, von-Mises, and maximum principal stresses at the contact region for brasson-bearing steel contact are analyzed. For the brass-on-bearing steel contact at a load of $10 \mathrm{~N}$, the variation of contact pressure after 100 FEM cycles is shown in Fig. 12(a). It is observed that the contact pressure varies from initial parabolic to a cupshaped distribution. This is due to the fact that, with the increase in cycles, the contact area increases and the contact pressure gets distributed over a larger area. Hence, a flat distribution of contact pressure is observed at the center of contact; while peaks are seen at the edges. The peaks may be caused because of stress concentration due to the sudden change in the contact area at the edges of contact. Similar peaks were also observed by Mukras et al. [21] during the wear prediction of oscillatory contacts. Von-Mises and maximum principal stress distributions were also obtained for the brass-on-bearing steel contact as observed in Fig. 12(b) \& (c). It is seen that both the stresses reduced with cycles because of increasing contact area. Also, the maximum principal stress was compressive in nature at the contact region. Moreover, in both cases, peaks were obtained at 


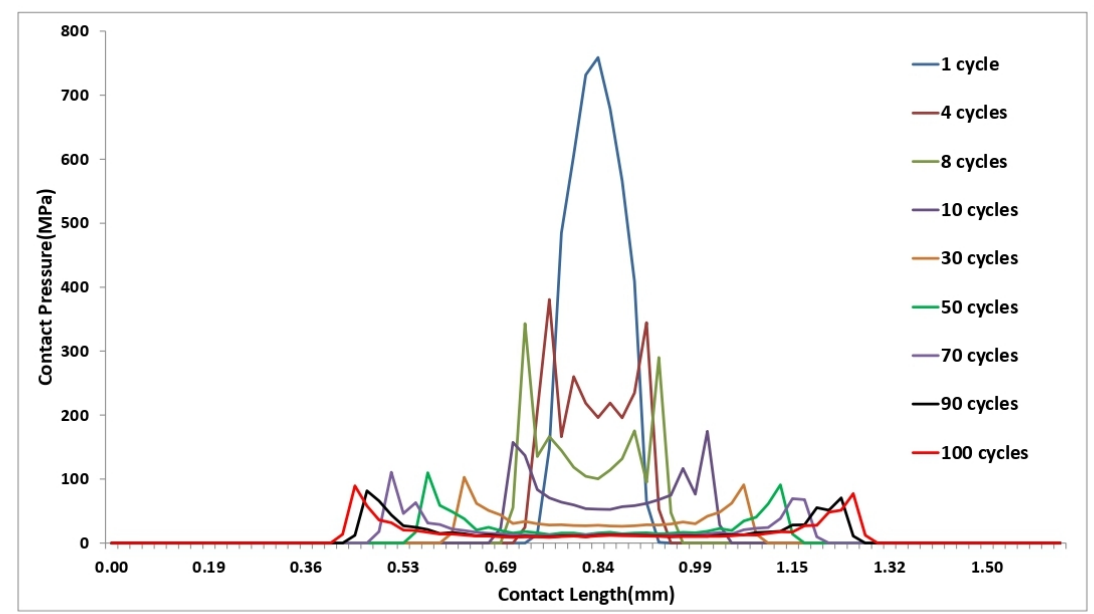

(a)

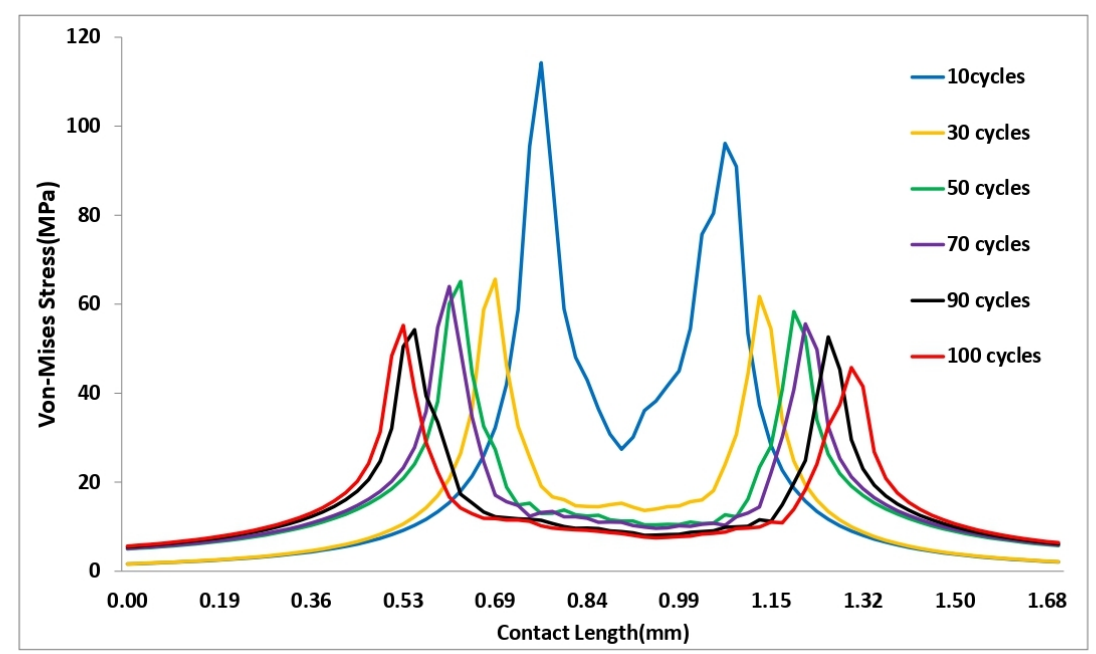

(b)

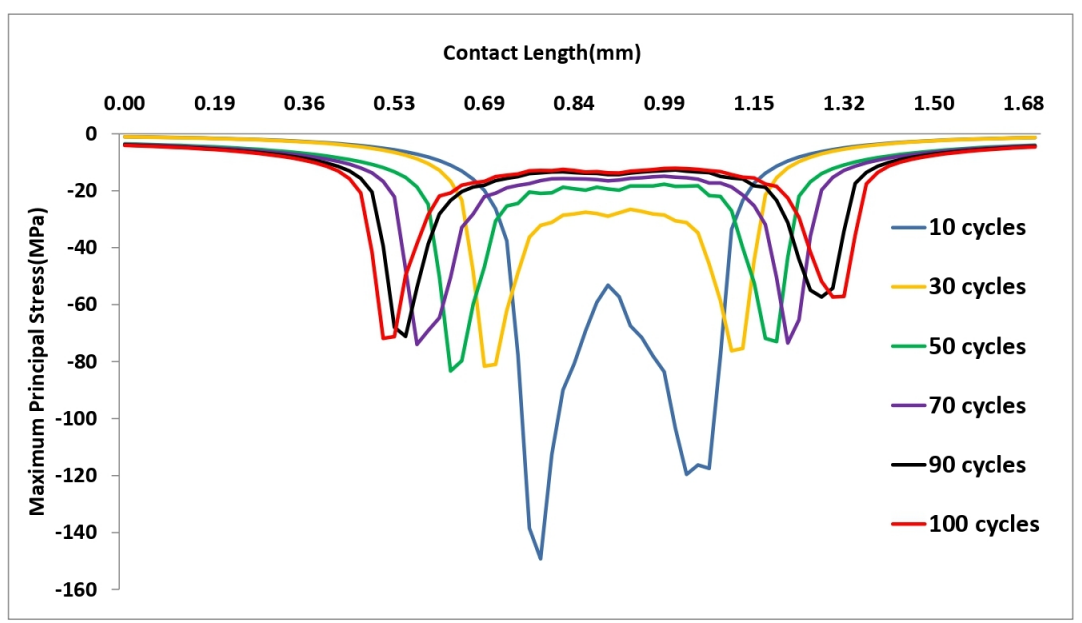

(c)

Fig. 12 (a) Contact Pressure (b) Von-Mises (c) Maximum Contact Pressure distribution for brasson-bearing steel contact for $10 \mathrm{~N}$ load and 100 FEM cycles

the edges due to stress concentration.

The variations of the stresses were compared for loads of $10 \mathrm{~N}, 20 \mathrm{~N}$ and $30 \mathrm{~N}$ after 100 FEM cycles in Fig. 13(a)-(c). There was an increase in the stresses at the contact region with the increase in loading. Moreover, the contact area also increased with an increase in loading. Finally, the contact pressure, vonMises and maximum principal stress nephograms for various loading conditions obtained after 100 FEM cycles are shown in Fig. 14(a)-(i).

Hence, it can be concluded that the wear simulation 


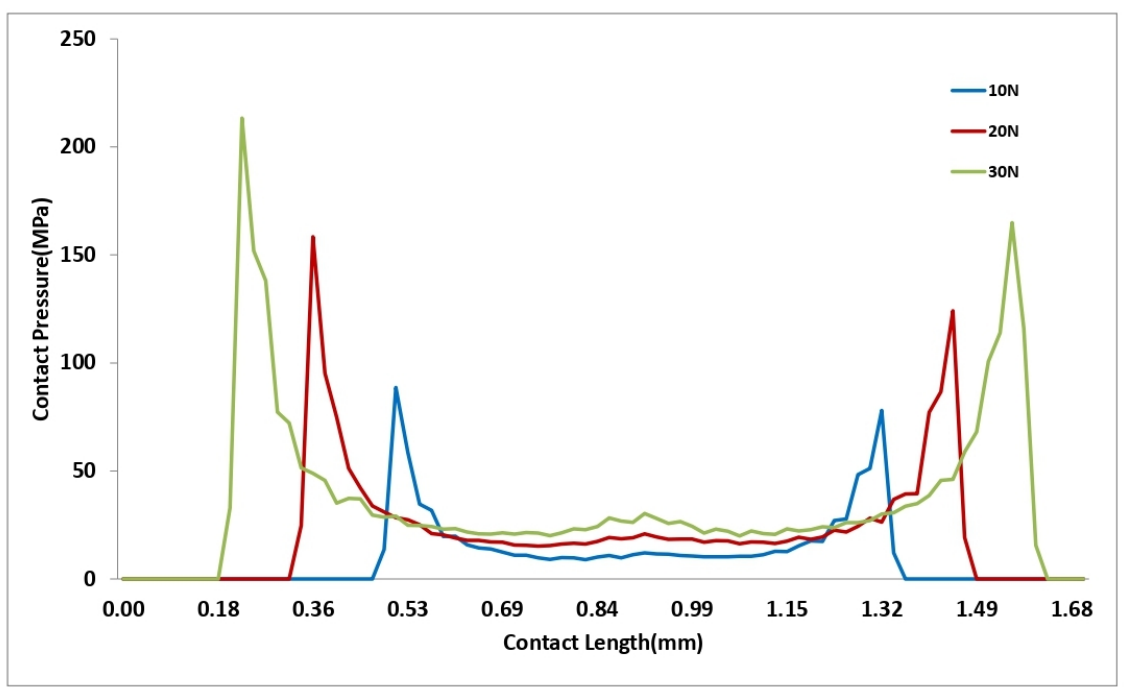

(a)

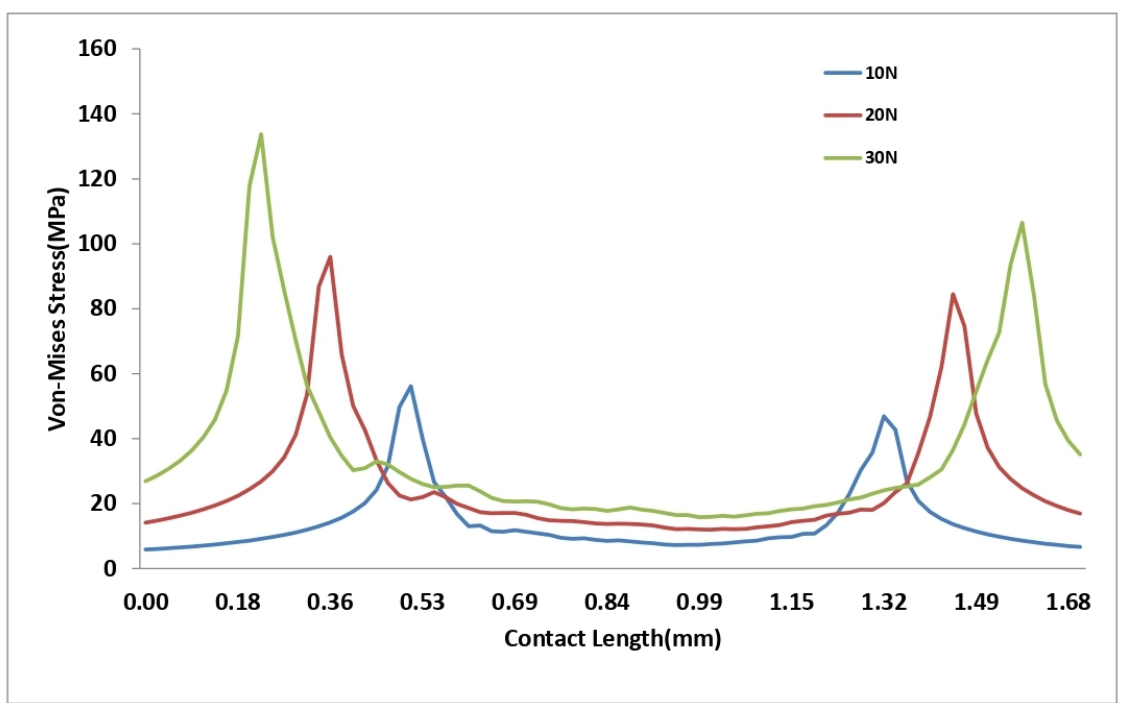

(b)

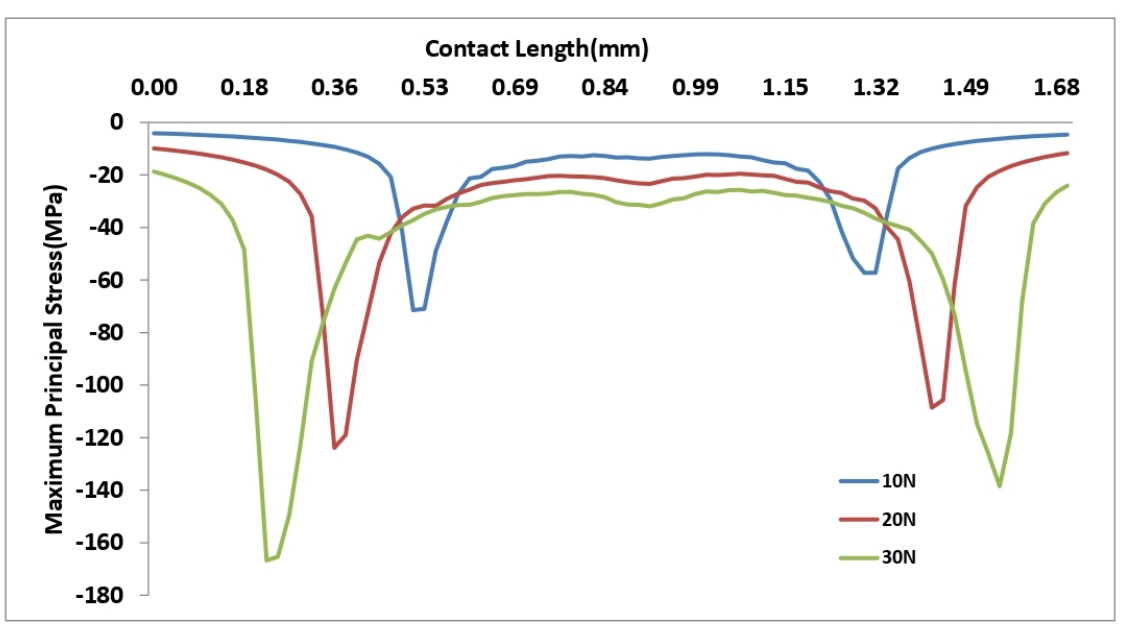

(c)

Fig. 13 (a) Contact Pressure (b) Von-Mises (c) Maximum Contact Pressure distribution for brass-on-bearing steel contact for $10 \mathrm{~N}, 20 \mathrm{~N}$ and $30 \mathrm{~N}$ loads and 100 FEM cycles 


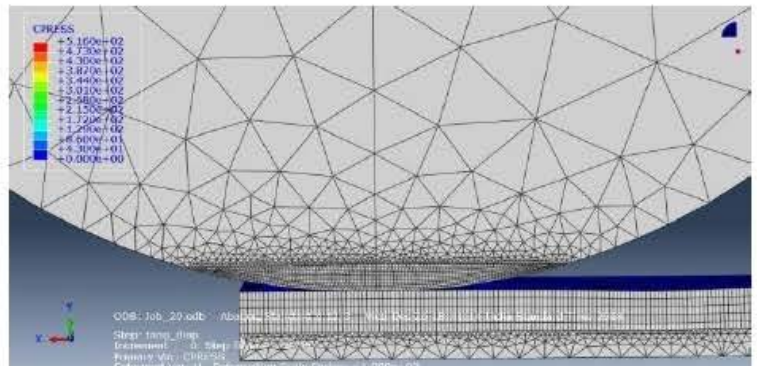

(a)

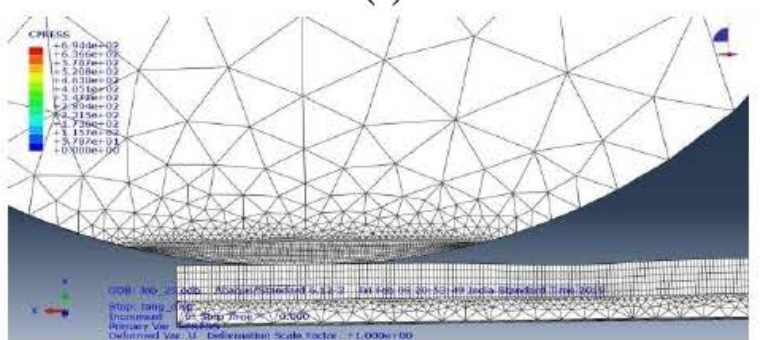

(c)

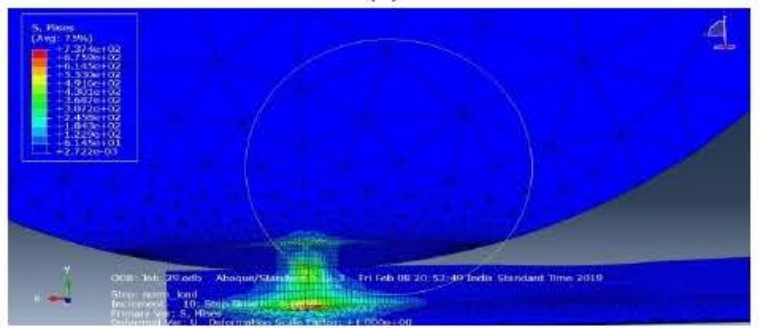

(e)

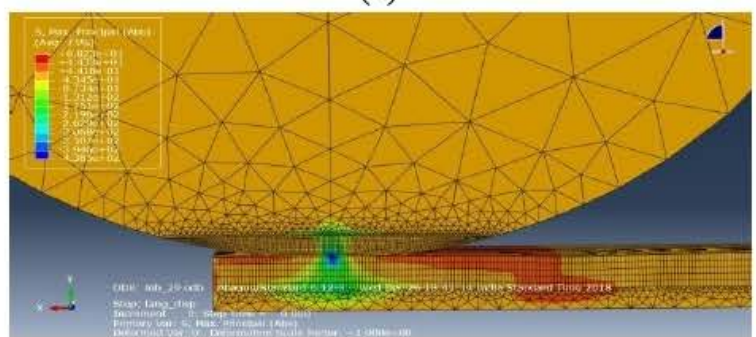

(g)

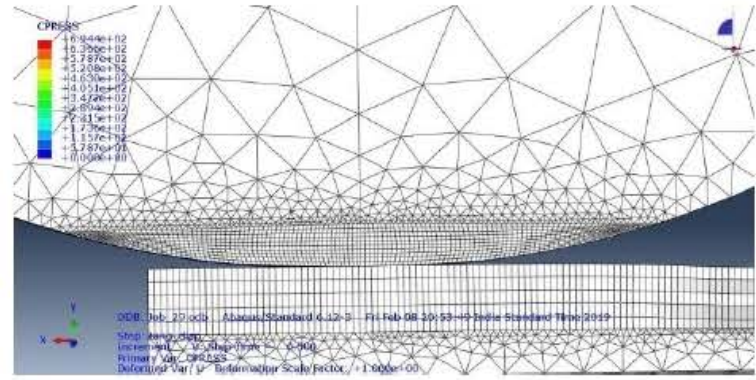

(b)

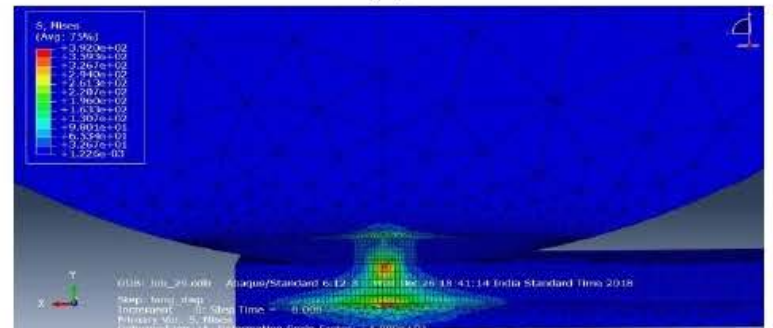

(d)

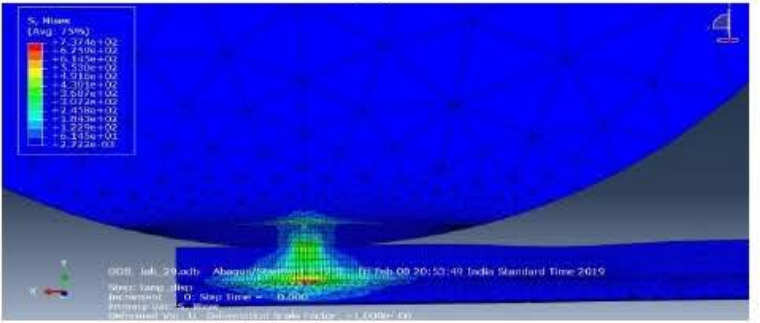

(f)

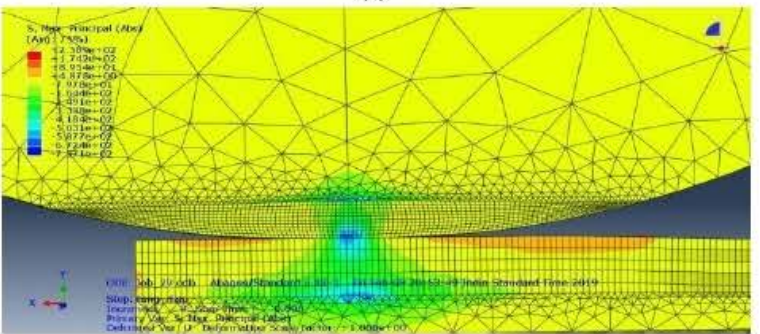

(h)

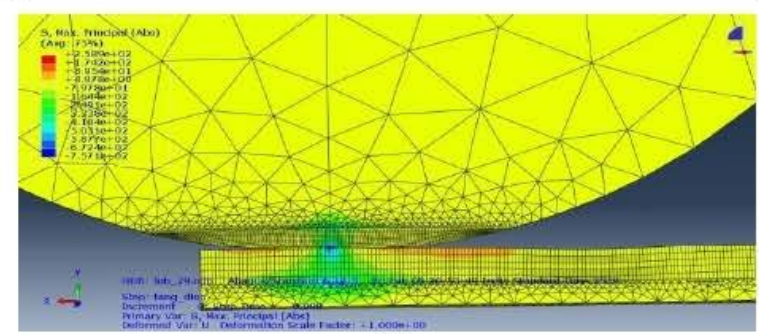

(i)

Fig. 14 Contact Pressure distribution for (a) 10N (b) 20N (c) 30N. Von-Mises stress distribution for (d) $10 \mathrm{~N}$ (e) $20 \mathrm{~N}$ (f) $30 \mathrm{~N}$. Maximum Principal Stress distribution for (g) $10 \mathrm{~N}$ (h) $20 \mathrm{~N}$ and (i) $30 \mathrm{~N}$ load

technique enabled in visualizing the distribution of contact pressure, Von-Mises and Maximum principal stress at the contact area with the progress of wear. Such distributions are difficult to achieve during experiments.

5.4 FEM based sliding wear prediction at various loading conditions

The wear simulation procedure is combined with the contact pressure approximation technique to predict the wear in brasson-bearing steel contact for $10 \mathrm{~N}, 20 \mathrm{~N}$ and $30 \mathrm{~N}$ loads after $500 \mathrm{~m}$ of sliding distance. The wear coefficient ' $k_{H}$ ' and friction coefficient ' $\mu$ ', from the experiments, were provided as inputs to the FEM model. Wear coefficients values of $k_{H}=4.28 \times 10^{-8} \mathrm{~mm}^{3} / \mathrm{Nm}, 3.67$ $\times 10^{-8} \mathrm{~mm}^{3} / \mathrm{Nm}$, and $3.72 \times 10^{-8} \mathrm{~mm}^{3} / \mathrm{Nm}$ were used for $10 \mathrm{~N}, 20 \mathrm{~N}$ and $30 \mathrm{~N}$ loads respectively. Similarly, the average coefficient of friction values from Table 4 was used in the simulations. Using 
the constant contact pressure approximation, the simulations were run for 120, 160 and 190 FEM cycles for all three loads.

The wear depth profile variation of the brass pins with cycles; obtained for all loads are shown in Fig. 15(a)-(c). As wear progresses, the pin wear depth increases continuously

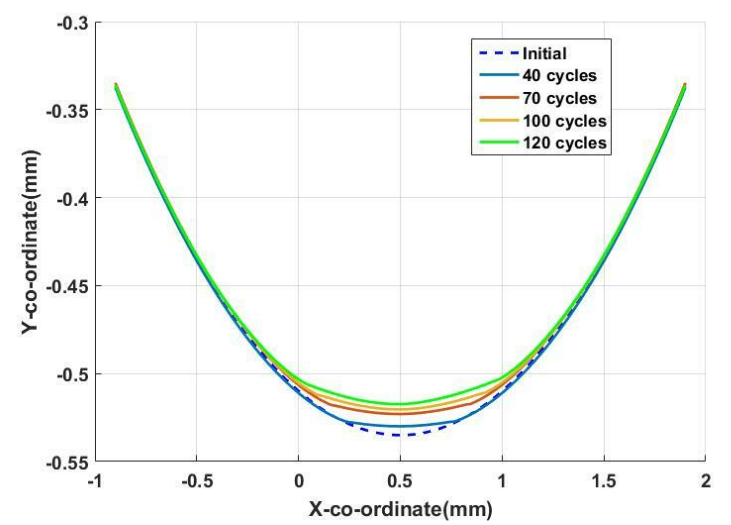

(a)

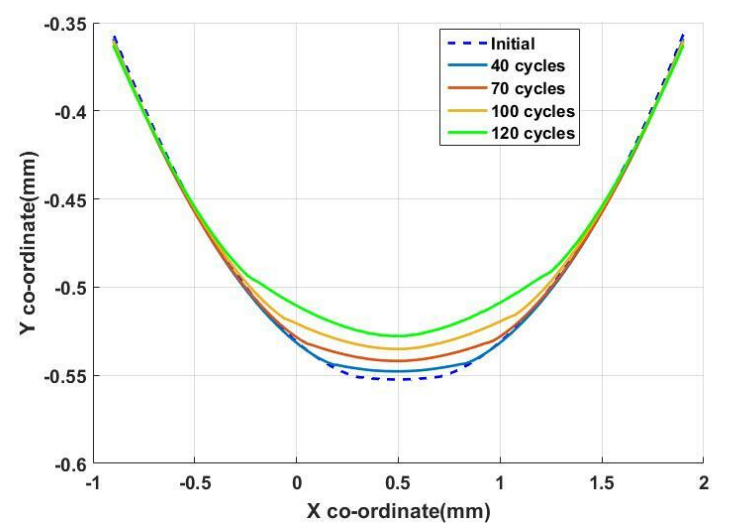

(b)

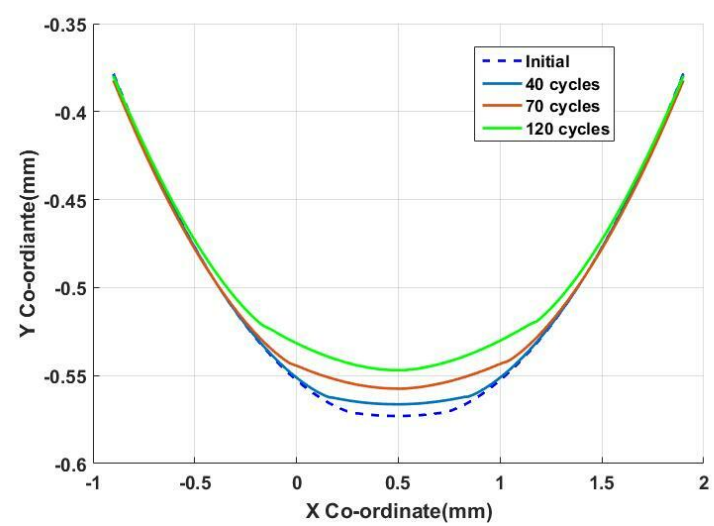

(c) and the profile of the pin shifts upwards. Similarly, the error in FEM wear prediction is shown in Table 6. The error varied from $1.19 \%$ for $10 \mathrm{~N}$ load to $16.9 \%$ for the $30 \mathrm{~N}$ load. This error may due to the average wear coefficient ' $k_{H}$ ' and coefficient of friction ' $\mu$ ' values used during simulations. In actual conditions, the coefficient of friction may vary with sliding distance. In a similar manner, there will also be a variation of wear coefficient ' $k_{H}$ ' with sliding distance. Hence, the assumption of average wear coefficient ' $k_{H}$ ' and coefficient of friction ' $\mu$ ' induced error in the results. Moreover, there was an increase in the error with the load. This might be due to the fact that at higher loads factors like temperature come into play which is not taken into consideration in the Archard's wear law. In addition, other factors like three-body wear, wear debris, material transfer, surface roughness, etc. should be incorporated in the model to increase the accuracy of the wear prediction. However, these factors make the sliding wear predictions even more complex.

Hence, in this paper, the large computational time requirement which was a major drawback of FEM wear predictions is minimized while maintaining an accuracy of about $83 \%$ in the wear predictions.

\section{Conclusions}

In this study, a FEM-based wear simulation procedure was developed to predict the sliding wear in PoD tribometers. A 3-D PoD model was created using ABAQUS. The material removal was modeled by incorporating the differential Archard's wear model and the UMESHMOTION subroutine. A constant contact pressure approximation technique was also proposed to decrease the simulation time without compromising the accuracy. Finally, the results were compared with the experiments for brass-on-bearing steel PoD contact. The conclusions that can be drawn from this study are:

- The FEM contact pressure distribution agreed quite well the Hertz contact pressure for a mesh size of $20 \mu \mathrm{m}$ at the contact region. An error of less than $1 \%$ was observed for the $10 \mathrm{~N}$ load and a maximum error of $3.37 \%$ was obtained for the $30 \mathrm{~N}$ load.

- A constant contact pressure approximation technique was proposed. The approximation technique incorporated the contact pressure variation at the contact region. It decreased the FEM wear cycles from about 250,000 to 120,160 and 190 for $10 \mathrm{~N}, 20 \mathrm{~N}$ and $30 \mathrm{~N}$ load.

- The wear simulation procedure along with the approximation technique was used to predict the wear in brass-on-bearing steel 3-D PoD contact. The wear depth obtained was compared with the experiments. Maximum accuracy of $98.81 \%$ was achieved for the $10 \mathrm{~N}$ and minimum accuracy of $83.10 \%$ for the $30 \mathrm{~N}$ load.

- Hence, the combination of FEM+ (UMESHMOTION + ALE) + approximation technique, decreased the simulation time while preserving the accuracy of the 3-D wear prediction.

Fig. 15 Wear Depth Profiles for (a) 10N (b) 20N (c) 30N loads

Table $6 \%$ Error between simulation and experimental wear depth for brass-on-bearing steel contact

\begin{tabular}{cccccc}
\hline Load & $\begin{array}{c}\text { Number of FEM } \\
\text { cycles }\end{array}$ & $\begin{array}{c}\text { Constant Contact Pressure } \\
\text { Approximation }(\mathrm{MPa})\end{array}$ & $\begin{array}{c}\text { Simulation Wear Depth } \\
(\mu \mathrm{m})\end{array}$ & $\begin{array}{c}\text { Experimental Wear } \\
\text { Depth }(\mu \mathrm{m})\end{array}$ & Error $(\%)$ \\
\hline $10 \mathrm{~N}$ & 120 & 17.88 & 382.60 & 377.95 & 1.19 \\
$20 \mathrm{~N}$ & 160 & 25.00 & 459.90 & 493.00 & 6.98 \\
$30 \mathrm{~N}$ & 190 & 37.91 & 704.84 & 602.46 & 16.90 \\
\hline
\end{tabular}




\section{References}

[1] Blau, P. J., "Fifty Years of Research on the Wear of Metals," Tribology International, 30, 5, 1997, 321-331.

[2] Meng, H. C. and Ludema, K. C., "Wear Models and Predictive Equations: Their Form and Content," Wear, 181-183, Part 2, 1995, 443-457.

[3] Archard, J. F., "Contact And Rubbing Of Flat Surfaces," Journal of Applied Physics, 24, 8, 1953, 981-988.

[4] Campañá, C. and Müser, M. H., "Practical Green's Function Approach to the Simulation of Elastic Semi-Infinite Solids," Physical Review B, 74, 7, 2006, 075420.

[5] Põdra, P. and Andersson, S., "Simulating Sliding Wear with Finite Element Method," Tribology International, 32, 2, 1999, 71-81.

[6] Ilincic, S., Vorlaufer, G., Fotiu, P. A., Vernes, A. and Franek, F., "Combined Finite Element-Boundary Element Method Modelling of Elastic Multi-Asperity Contacts," Proceedings of the Institution of Mechanical Engineers, Part J: Journal of Engineering Tribology, 223, 5, 2009, 767-776.

[7] Ilincic, S., Tungkunagorn, N., Vernes, A., Vorlaufer, G., Fotiu, P. A. and Franek, F., "Finite and Boundary Element Method Contact Mechanics on Rough, Artificial Hip Joints," Proceedings of the Institution of Mechanical Engineers, Part J: Journal of Engineering Tribology, 225, 11, 2011, 1081-1091.

[8] Jackson, R. L. and Streator, J. L., “A Multi-Scale Model for Contact between Rough Surfaces," Wear, 261, 11-12, 2006, 1337-1347.

[9] Hegadekatte, V., Kurzenhäuser, S., Huber, N. and Kraft, O., "A Predictive Modeling Scheme for Wear in Tribometers," Tribology International, 41, 11, 2008, 1020-1031.

[10] Ashraf, M. A., Ahmed, R., Ali, O., Faisal, N. H., El-Sherik, A. M. and Goosen, M. F. A., "Finite Element Modeling of Sliding Wear in a Composite Alloy Using a Free-Mesh," Journal of Tribology, 137, 3, 2015, 031605.

[11] Tavoosi, H., Ziaei-Rad, S., Karimzadeh, F. and Akbarzadeh, S., "Experimental and Finite Element Simulation of Wear in Nanostructured Nial Coating," Journal of Tribology, 137, 4, 2015, 041601.

[12] Molinari, J. F., Ortiz, M., Radovitzky, R. and Repetto, E. A., "FiniteElement Modeling of Dry Sliding Wear in Metals," Engineering
Computations, 18, 2001, 592-610.

[13] Hegadekatte, V., Huber, N. and Kraft, O., "Finite Element Based Simulation of Dry Sliding Wear," Modelling and Simulation in Materials Science and Engineering, 13, 1, 2005, 57-75.

[14] Öqvist, M., "Numerical Simulations of Mild Wear Using Updated Geometry with Different Step Size Approaches," Wear, 249, 1-2, 2001, 6-11.

[15] Ding, J., McColl, I. R., Leen, S. B. and Shipway, P. H., "A Finite Element Based Approach to Simulating the Effects of Debris on Fretting Wear," Wear, 263, 1-6, 2007, 481-491.

[16] Arjmandi, M., Ramezani, M., Giordano, M. and Schmid, S., "Finite Element Modelling of Sliding Wear in Three-Dimensional Woven Textiles," Tribology International, 115, 2017, 452-460.

[17] Strömberg, N., "Finite Element Treatment of Two-Dimensional Thermoelastic Wear Problems," Computer Methods in Applied Mechanics and Engineering, 177, 3-4, 1999, 441-455.

[18] Mattei, L. and Di Puccio, F., "Influence of the Wear Partition Factor on Wear Evolution Modelling of Sliding Surfaces," International Journal of Mechanical Sciences, 99, 2015, 72-88.

[19] Curreli, C., Di Puccio, F. and Mattei, L., "Application of the Finite Element Submodeling Technique in a Single Point Contact and Wear Problem," International Journal of Numerical Methods in Engineering, 116, 10-11, 2018, 708-722.

[20] Kim, N. H., Won, D., Burris, D., Holtkamp, B., Gessel, G. R., Swanson, P. and Sawyer, W. G., "Finite Element Analysis and Experiments of Metal/Metal Wear in Oscillatory Contacts," Wear, 258, 11-12, 2005, 1787-1793.

[21] Mukras, S., Kim, N. H., Sawyer, W. G., Jackson, D. B. and Bergquist, L. W., "Numerical Integration Schemes and Parallel Computation for Wear Prediction Using Finite Element Method," Wear, 266, 7-8, 2009, 822-831.

[22] Bortoleto, E. M., Rovani, A. C., Seriacopi, V., Profito, F. J., Zachariadis, D. C., Machado, I. F., Sinatora, A. and Souza, R. M., "Experimental and Numerical Analysis of Dry Contact in the Pin on Disc Test," Wear, 301, 1-2, 2013, 19-26.

[23] Johnson, K. L., "Contact Mechanics," Cambridge University Press, Cambridge, 1985, 299.

[24] Dassault Systèmes Simulia, "Analysis User's Manual Volume 2: Analysis," Abaqus 6.12 II., 2012. 